\title{
Structure and Absolute Configuration of Secondary Metabolites from Two Strains of Streptomyces chartreusis Associated with Attine Ants
}

\author{
Humberto E. Ortega, ${ }^{\oplus a}$ João M. Batista Jr., ${ }^{\circledR *, b, c}$ Weilan G. P. Melo, ${ }^{\circledR a}$ \\ Gabriela T. de Paula and Mônica T. Pupo ${ }^{\circledR} * a$ \\ ${ }^{\mathrm{a}}$ Faculdade de Ciências Farmacêuticas de Ribeirão Preto (FCFRP), \\ Universidade de São Paulo (USP), 14040-903 Ribeirão Preto-SP, Brazil \\ ${ }^{b}$ Departamento de Química, Universidade Federal de São Carlos (UFSCar), \\ 13565-905 São Carlos-SP, Brazil \\ 'Instituto de Ciência e Tecnologia, Universidade Federal de São Paulo (UNIFESP), \\ 12231-280 São José dos Campos-SP, Brazil
}

\begin{abstract}
The antibiotic streptazolin (1), its $E$-isomer (2), along with the stereoisomers strepchazolin A (3) and strepchazolin B (4) and the inorganic compound cyclooctasulfur (5) were produced in solid culture by Streptomyces chartreusis ICBG377, which was isolated from the fungal garden of the leaf-cutter ant Acromyrmex subterraneus brunneus. This is the first time compound $\mathbf{2}$ is reported as a natural product. Compound $\mathbf{5}$, which showed antagonist activity against the specialized pathogenic fungus Escovopsis sp., was also produced by Streptomyces chartreusis ICBG323, isolated from the exoskeleton of winged male of Mycocepurus goeldii. The absolute configurations of $\mathbf{3}$ and $\mathbf{4}$ were confirmed by the combination of vibrational circular dichroism (VCD) spectroscopy and density functional theory (DFT) calculations. These results clearly demostrate the power of VCD to tell apart epimeric natural products. Compounds 1, 3 and $\mathbf{4}$ were produced by geographically distant but phylogenetically close strains, S. chartreusis ICBG 377 isolated in Brazil, and S. chartreusis NA02069, a marine sediment strain isolated in China.
\end{abstract}

Keywords: Acromyrmex subterraneus brunneus, Mycocepurus goeldii, leaf-cutter ant, strepchazolins A and B, VCD, DFT

\section{Introduction}

Fungus-growing ants (tribe Attini) comprise more than 230 species, all of which depend on the cultivation of fungal gardens for food. They can be divided into five distinct agricultural systems: lower agriculture; coral fungus agriculture; yeast agriculture; generalized higher agriculture; and leaf-cutter agriculture that has evolved more recently to become the dominant herbivores of the New World tropics. The leaf-cutter agriculture involves different species of the two major genera, Atta and Acromyrmex, with the ability to cut and process fresh vegetation as a nutritional substrate for their fungal crop. ${ }^{1}$ Atta and Acromyrmex are considered the highly evolved attines while lower attines comprise several genera including Mycocepurus, Myrmicocrypta, Apterostigma, Mycetophylax, Mycetarotes,

*e-mail: batista.junior@unifesp.br; mtpupo@fcfrp.usp.br
Mycetosoritis, and Cyphomyrmex, which retain more primitive features. ${ }^{1-3}$

Several new and known biologically active compounds have been identified from actinobacteria (Streptomyces and Pseudonocardia) isolated from fungus-growing ant colonies. ${ }^{4-7}$ The first example was the new cyclic depsipeptide dentigerumycin, produced by the symbiotic Pseudonocardia sp., isolated from the exoskeleton of the coral fungus agriculture ant Apterostigma dentigerum. This compound has a selective inhibition against the specialized pathogenic fungus Escovopsis sp., found only in fungus-growing ants colonies, and also a potent inhibitory activity against several Candida albicans strains. ${ }^{8}$ As part of the International Cooperative Biodiversity Group Program in Brazil (ICBG-Brazil), ${ }^{9}$ we have investigated the small molecules produced by Streptomyces chartreusis ICBG377, isolated from the fungal garden of the leafcutter ant Acromyrmex subterraneus brunneus; and from 
Streptomyces chartreusis ICBG323, isolated from the exoskeleton of winged males of Mycocepurus goeldii. S. chartreusis ICBG377 produced streptazolin (1), its $E$-isomer (2), strepchazolin A (3), strepchazolin B (4) and cyclooctasulphur (5) (Figure 1); while compound $\mathbf{5}$ was also produced by $S$. chartreusis ICBG323. It is noteworthy that this is the first time compound $\mathbf{2}$ is reported as a natural product.

In this paper, besides reporting the isolation and structural characterization of compounds $\mathbf{1 - 5}$, we describe the use of vibrational circular dichroism (VCD) spectroscopy and density functional theory (DFT) calculations to confirm the absolute configuration of the stereoisomers 3 and $\mathbf{4}$. The unambiguous assignment of absolute configuration is a common bottleneck in the natural product isolation pipeline,,$^{10}$ especially when epimers are concerned. Finally, the possible ecological function of $\mathbf{5}$ in fungus-growing ant ecosystems is also discussed.

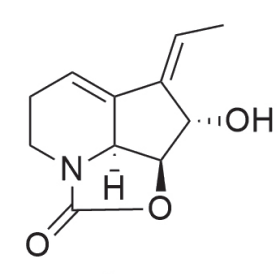

1

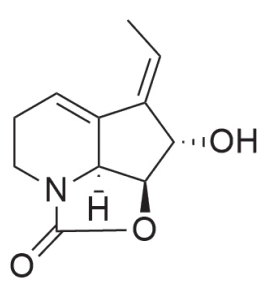

2

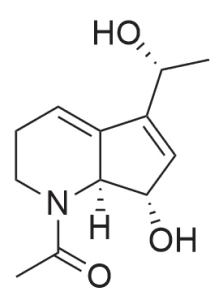

3

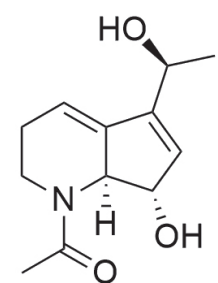

4

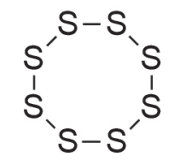

5
Figure 1. Compounds isolated from Streptomyces chartreusis ICBG377.

\section{Results and Discussion}

Strain ICBG377 was isolated from the fungal garden of Acromyrmex subterraneus brunneus and strain ICBG323 was isolated from winged male Mycocepurus goeldii. Both strains were identified by $16 \mathrm{~S}$ rRNA sequencing as Streptomyces chartreusis. Several antitumor and antibiotics compounds have been reported from soil S. chartreusis strains, such as cephamycins SF-1623 and SF-1623B; chartreusin, chrymutasins, calcimycin, cezomycin, and others. ${ }^{11-14}$ S. chartreusis ICBG377 and ICBG323 inhibited the growth of Escovopsis sp. in antagonism bioassays (Figures S1 and S2, respectively, Supplementary Information (SI) section). Therefore, strains ICBG377 and ICBG323 were grown on ISP-2 agar, and the cultures were extracted with EtOAc for chemical studies.
The two major compounds detected by highperformance liquid chromatography ultraviolet detector (HPLC-UV) from the ethyl acetate (EtOAc) extract of S. chartreusis ICBG377 were streptazolin (1) and its $E$-isomer (2) (Figure S3, SI section). They were identified by comparison of their nuclear magnetic resonance (NMR) and mass spectrometry (MS) data with that in the literature (Figures S4-S7, SI section). ${ }^{15,16}$ Compound 1 has only been isolated from the genus Streptomyces. It is an unusual antibiotic and antifungal compound, ${ }^{15}$ which possesses its major structural features composed by a 1,2,5,6-tetrahydropyridine ring system, a cyclourethane, and an exocyclic ethylidene side chain. ${ }^{17}$ Structural variants of streptazolin (1) such as 3,9-dihydrostreptazolin and Diels-Alder adducts with naphthoquinones show enhanced antimicrobial and cytotoxic activity. ${ }^{18}$ Recent studies have found that streptazolin increases bacterial killing and the elaboration of immunostimulatory cytokines by macrophages in vitro. ${ }^{19}$ The $E$-isomer of streptazolin (2) has been reported as an undesired side product in the synthesis of the streptazolin; ${ }^{17}$ however, it had not been previously reported as a natural product.

Compound 3 gave a peak in the high-resolution electrospray ionization mass spectrometry (HRESIMS) consistent with a molecular formula $\mathrm{C}_{12} \mathrm{H}_{17} \mathrm{NO}_{3}$ (Figure S8, SI section). The UV and NMR data of $\mathbf{3}$ (Table 1 and Figures S9-S13, SI section) indicated that it is strepchazolin A. ${ }^{20}$ Compound $\mathbf{3}$ does not contain the cyclourethane ring as observed in $\mathbf{1}$. Instead, compound $\mathbf{3}$ has an acetyl group bound to the nitrogen atom, two hydroxyl groups at C-6 and C-9, and a double bound between C-7 and C-8. Both compounds 3 and $\mathbf{1}$ have a double bound between C-3 and C-4 (NMR data comparison in Table 1).

Compound $\mathbf{4}$ gave the same peak in the HRESIMS as observed for $\mathbf{3}$ (Figure S14, SI section). The UV and NMR data obtained for $\mathbf{4}$ are very similar to that of $\mathbf{3}$ (Table 1 and Figures S15-S23, SI section). There are small differences in hydrogen and carbon chemical shifts between $\mathbf{3}$ and $\mathbf{4}$ : $\mathrm{H}-3\left(\delta_{\mathrm{H}} 6.01\right.$ for 3 and $\delta_{\mathrm{H}} 5.90$ for 4$), \mathrm{C}-3\left(\delta_{\mathrm{C}} 115.8\right.$ for $\mathbf{3}$ and $\delta_{\mathrm{C}} 115.3$ for 4$)$, C-7 $\left(\delta_{\mathrm{C}} 131.0\right.$ for 3 and $\delta_{\mathrm{C}} 129.8$ for $\left.\mathbf{4}\right)$, C-8 $\left(\delta_{\mathrm{C}} 146.2\right.$ for 3 and $\delta_{\mathrm{C}} 146.7$ for 4$)$ and C-10 $\left(\delta_{\mathrm{C}} 21.9\right.$ for 3 and $\delta_{\mathrm{C}} 22.6$ for 4). Gradient-selected correlation spectroscopy (gCOSY) and gradient-selected heteronuclear multiple bond coherence (gHMBC) correlations observed for $\mathbf{4}$ were identical to those observed for $\mathbf{3}$, indicating that it is strepchazolin B. ${ }^{20}$

The relative configurations of compounds 3 and $\mathbf{4}$ were determined by nuclear Overhauser spectroscopy (NOESY) experiments. The key nuclear Overhauser effect (NOE) correlations are presented in Figure 2. Hydrogen H-5 
Table 1. ${ }^{1} \mathrm{H}(500 \mathrm{MHz})$ and ${ }^{13} \mathrm{C}$ NMR $(100 \mathrm{MHz})$ data for strepchazolin A (3) and strepchazolin B (4) $\left(\mathrm{CDCl}_{3}\right)$ compared to NMR data for streptazolin (1) $\left(\mathrm{CDCl}_{3}\right)$

\begin{tabular}{|c|c|c|c|c|c|c|}
\hline \multirow{2}{*}{ Position } & \multicolumn{2}{|c|}{ Strepchazolin A $(\mathbf{3})^{\mathrm{a}}$} & \multicolumn{2}{|c|}{ Strepchazolin B (4) } & \multicolumn{2}{|c|}{ Streptazolin (1) 17} \\
\hline & $\delta_{\mathrm{C}} / \mathrm{ppm}$, type & $\delta_{\mathrm{H}} / \mathrm{ppm}$, mult. $(J / \mathrm{Hz})$ & $\delta_{\mathrm{C}} / \mathrm{ppm}$, type & $\delta_{\mathrm{H}} / \mathrm{ppm}$, mult. $(J / \mathrm{Hz})$ & $\delta_{\mathrm{C}} / \mathrm{ppm}$, type & $\delta_{\mathrm{H}} / \mathrm{ppm}$, mult. $(\mathrm{J} / \mathrm{Hz})$ \\
\hline 1 & $45.1, \mathrm{CH}_{2}$ & $\begin{array}{l}3.17, \operatorname{td}(11.3,3.9) \\
3.72, \mathrm{dt}(12.0,3.6)\end{array}$ & $45.1, \mathrm{CH}_{2}$ & $\begin{array}{l}3.16, \operatorname{td}(11.2,3.8) \\
3.71, \mathrm{dt}(12.0,3.6)\end{array}$ & $39.9, \mathrm{CH}_{2}$ & $3.36-3.51, \mathrm{~m}$ \\
\hline 2 & $25.2, \mathrm{CH}_{2}$ & $2.31, \mathrm{~m}$ & $25.2, \mathrm{CH}_{2}$ & $2.28, \mathrm{~m}$ & $22.8, \mathrm{CH}_{2}$ & $\begin{array}{c}2.13-2.25, \mathrm{~m} \\
2.51, \mathrm{dtd}(16.7,7.2,3.3)\end{array}$ \\
\hline 3 & $115.8, \mathrm{CH}$ & 6.01 , quint (3.4) & $115.3, \mathrm{CH}$ & $5.90, \mathrm{~m}$ & $118.9, \mathrm{CH}$ & 6.02-6.07, m \\
\hline 4 & $140.2, \mathrm{C}$ & - & $140.5, \mathrm{C}$ & - & $142.8, \mathrm{C}$ & - \\
\hline 5 & $67.5, \mathrm{CH}$ & 4.35 , br s & $67.5, \mathrm{CH}$ & 4.34 , br s & $59.1, \mathrm{CH}$ & $4.26-4.31, \mathrm{~m}$ \\
\hline 6 & $79.8, \mathrm{CH}$ & $4.61, \mathrm{br} \mathrm{s}$ & $79.8, \mathrm{CH}$ & 4.60, br s & $81.5, \mathrm{CH}$ & $4.73, \mathrm{~d}(6.8)$ \\
\hline 7 & $131.0, \mathrm{CH}$ & 5.96 , br s & $129.8, \mathrm{CH}$ & 5.98 , br s & $74.5, \mathrm{CH}$ & 4.88, br s \\
\hline 8 & 146.2, C & - & 146.7, C & - & 139.1, C & - \\
\hline 9 & $64.5, \mathrm{CH}$ & $4.58, \mathrm{~m}$ & $64.7, \mathrm{CH}$ & $4.58, \mathrm{~m}$ & 123.7, CH & $6.15, \mathrm{q}(7.3)$ \\
\hline 10 & $21.9, \mathrm{CH}_{3}$ & $1.44, \mathrm{~d}(6.42)$ & 22.6, $\mathrm{CH}_{3}$ & $1.41, \mathrm{~d}(6.56)$ & $14.9, \mathrm{CH}_{3}$ & $1.91, \mathrm{~d}(7.3)$ \\
\hline 11 & 173.0, C & - & $172.9, \mathrm{C}$ & - & $159.3, \mathrm{C}$ & - \\
\hline 12 & $23.1, \mathrm{CH}_{3}$ & $2.19, \mathrm{~s}$ & 23.2, $\mathrm{CH}_{3}$ & $2.18, \mathrm{~s}$ & - & - \\
\hline 6-O-H & - & $5.86, \mathrm{~s}$ & - & $5.86, \mathrm{~s}$ & - & - \\
\hline
\end{tabular}

${ }^{\mathrm{a}} \mathrm{NMR}$ data previously published for 3 and $\mathbf{4}$ were recorded in $\mathrm{CD}_{3} \mathrm{OD} ;{ }^{20}{ }^{\mathrm{b}} \mathrm{H}(400 \mathrm{MHz})$ and ${ }^{13} \mathrm{C} \mathrm{NMR}(100.6 \mathrm{MHz})$ data for $\mathbf{1}$ obtained in $\mathrm{CDCl}_{3} ;{ }^{1} \mathrm{H} \mathrm{NMR}$ data for $\mathbf{3}$ and $\mathbf{4}$ were acquired in a DRX-500 Bruker spectrometer and ${ }^{13} \mathrm{C}$ NMR data in a DRX-400 Bruker spectrometer in our experiments.

presents a correlation with the hydrogen of the hydroxyl group at C-6 in both compounds, indicating that they are on the same face of the molecules. Therefore, their absolute configuration could be only $5 S, 6 S$ or $5 R, 6 R$. Compounds 3 and $\mathbf{4}$ also share other common NOE correlations: H-3 and $\mathrm{H}-9, \mathrm{H}-3$ and $\mathrm{H}-10$, as well as between $\mathrm{H}-10$ and H-7 (Figures S13 and S23, SI section). Based on that, compounds $\mathbf{3}$ and $\mathbf{4}$ are concluded to be epimers at C-9. The different arrangement of the substituents at C-9 accounts for the distinct chemical shifts of H-3, C-3, C-7, C-8 and $\mathrm{C}-10$ in both compounds. Compounds $\mathbf{3}$ and $\mathbf{4}$ presented different retention times in HPLC analysis (see Figure S3, SI section), reinforcing that they are steroisomers. Strepchazolin B (4) eluted first than strepchazolin A (3) using $\mathrm{C}_{6}$-Phenyl HPLC column.

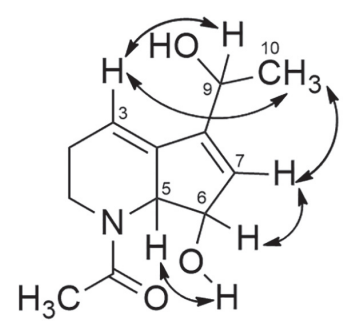

Figure 2. Key NOE correlations of compounds 3 and $\mathbf{4}$.

Once the planar structures of $\mathbf{3}$ and $\mathbf{4}$ were elucidated, we proceeded with attempts to assign their absolute configurations. To that end, experimental infrared (IR)/ VCD spectra were recorded for both compounds in methanol- $d_{4}$, which were then compared to the theoretical data obtained for both diastereoisomers possible. The comparison between observed and calculated spectra at the B3PW91/PCM(MeOH)/6-311G(d,p) level (Figure 3) allowed for the unambiguous determination of the absolute configuration of compound (-)-3 as $(5 S, 6 S, 9 R)$ and (-)-4 as $(5 S, 6 S, 9 S)$. Despite the high degree of similarity between the IR and VCD spectra of $\mathbf{3}$ and $\mathbf{4}$, the VCD band at around $1385 \mathrm{~cm}^{-1}$, which presented opposite signs for both epimers and was consistently reproduced by the calculations, represented the key spectral marker considered for these assignments. This band arises predominantly from the inplane bending of $\mathrm{H}-9$ coupled with the symmetrical bending of the methyl group at $\mathrm{C}-10$, as well as with the $\mathrm{C}-\mathrm{C}$ stretches between C-4/C-8 and C-8/C-9. The fact that these particular vibrations involve the atoms directly linked to chiral center at C-9 provides a higher level of confidence for this assignment. The lowest-energy conformers identified for both configurations at C-9 (Figure 4) also help explain most of the above-mentioned NMR data, such as the NOE correlations that are common to both $\mathbf{3}$ and $\mathbf{4}$. Interestingly, for strepchazolin $\mathrm{A} \mathrm{(3)}$ the $\mathrm{OH}$ group points predominantly towards H-3, while for strepchazolin B (4) the same group at C-9 points away from $\mathrm{H}-3$ for most conformers. These findings may be responsible for the small difference in 


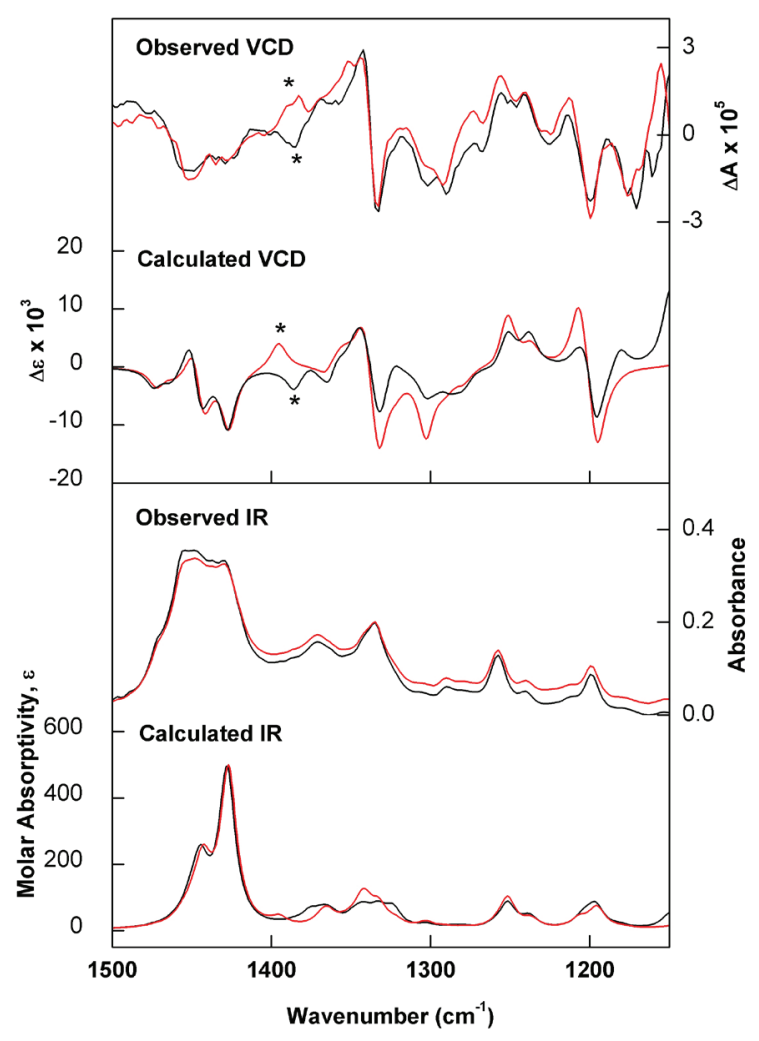

Figure 3. Comparison of the observed IR and VCD spectra of (-)-3 (black trace) and (-)-4 (red trace) with the calculated (B3PW91/ $\mathrm{PCM}(\mathrm{MeOH}) / 6-311 \mathrm{G}(\mathrm{d}, \mathrm{p}))$ IR and VCD spectra of the Boltzmann average of the four lowest-energy conformers identified for strepchazolin A (black trace) and strepchazolin B (red trace). The asterisks represent the key VCD bands considered for the assignment of (-)-3 as $(5 S, 6 S, 9 R)$ and $(-)-\mathbf{4}$ as $(5 S, 6 S, 9 S)$. the chemical shift observed for H-3 in both epimers due to the deshielding anisotropic effect of the oxygen lonepairs. The absolute configurations of $\mathbf{3}$ and $\mathbf{4}$ were recently determined by X-ray and Mosher's method, respectively, ${ }^{20}$ and our VCD data are in agreement with the previously established stereochemistry.

The wealth of structural and conformational information obtained from vibrational spectroscopy combined with the extra sensitivity to molecular chirality provided by VCD has made the latter a valuable new addition to the natural product chemistry toolbox. ${ }^{21}$

Cyclooctasulfur (5) was identified as the major compound by gas chromatography-mass spectrometry (GC-MS) (Figures S24-S25, SI section) from the unique bioactive fractions of both $S$. chartreusis strains (ICBG377 and ICBG323) against Escovopsis sp. (Figures S26-S27, SI section). Compound 5 has been previously reported from the North Sea Streptomyces GWS-BW-H5. ${ }^{22}$ Under normal conditions, sulfur atoms form cyclic octatomic molecules. The element sulfur has been used as antimicrobial agent, insecticide, fumigant, etc. ${ }^{23}$ So, S. chartreusis ICBG377 and ICBG323 could use 5 to help in the growth control of the pathogenic fungus Escovopsis. Compounds 1-4 did not show antifungal activity against Escovopsis.

Streptazolin (1), strepchazolin A (3) and strepchazolin B (4) were reported recently from S. chartreusis NA02069 (MH540322) isolated from marine sediment. ${ }^{20}$ Compound $\mathbf{3}$ was published with weak
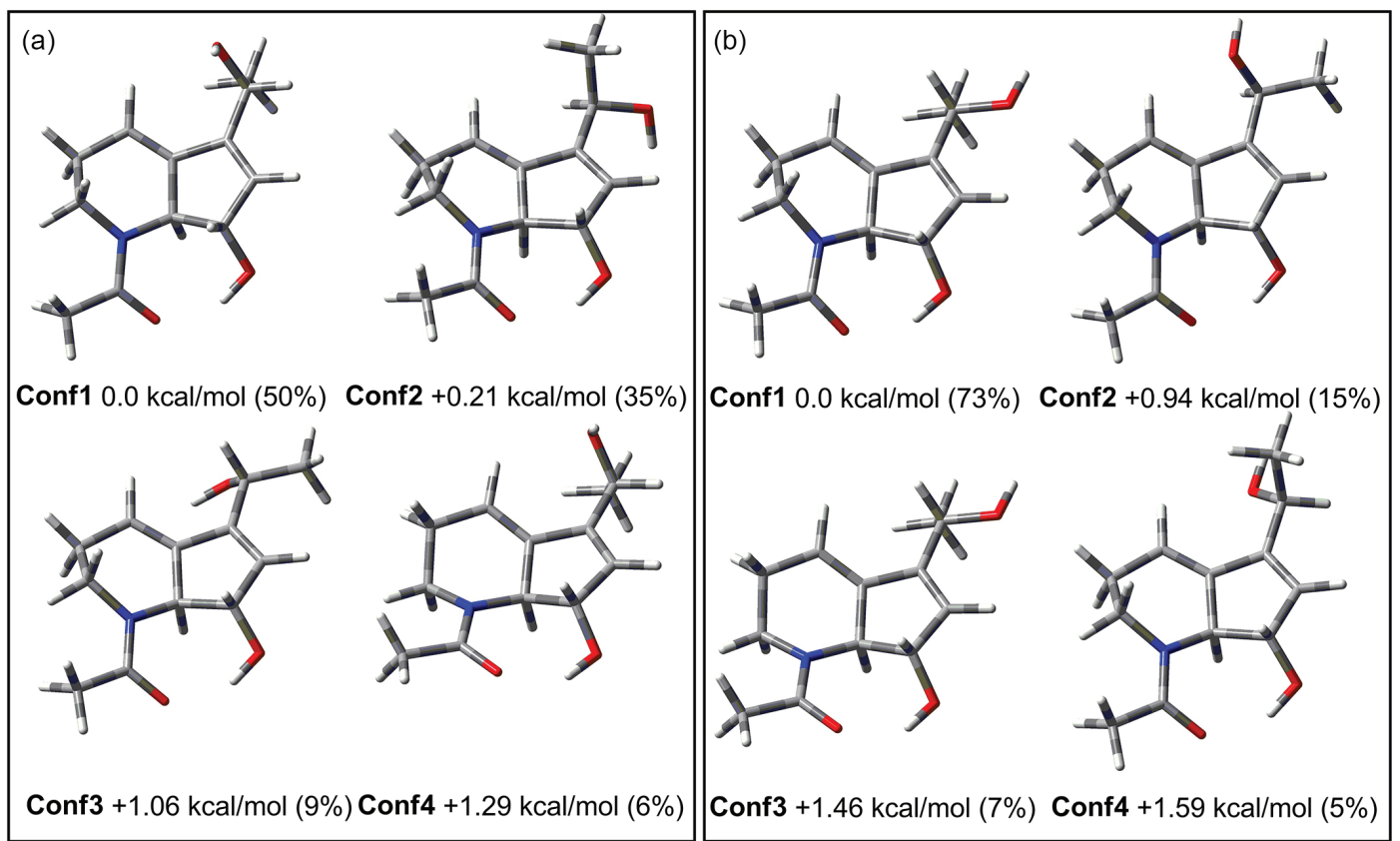

Figure 4. (a) Structures, relative Gibbs free energies (referenced to Conf1, G $=-469127.091 \mathrm{kcal} \mathrm{mol}^{-1}$ ), and Boltzmann population (\%) of the four lowest-energy conformers of strepchazolin A (3) at the B3PW91/PCM(MeOH)/6-311G(d,p) level. (b) Structures, relative Gibbs free energies (referenced to Conf1, $\mathrm{G}=-469126.203 \mathrm{kcal} \mathrm{mol}^{-1}$ ), and Boltzmann population (\%) of the four lowest-energy conformers of strepchazolin B (4) at the B3PW91/ $\mathrm{PCM}(\mathrm{MeOH}) / 6-311 \mathrm{G}(\mathrm{d}, \mathrm{p})$ level. 
anti-Bacillus subtilis activity with minimal inhibitory concentration (MIC) value of $64.0 \mu \mathrm{M}$, and weak inhibitory activity against acetylcholinesterase (AChE) in vitro with half maximal inhibitory concentration $\left(\mathrm{IC}_{50}\right)$ value of $50.6 \mu \mathrm{M}$, while compound $\mathbf{4}$ was almost inactive. ${ }^{20}$

A phylogenetic tree was constructed and included 24 strains of the genus Streptomyces from databases, two antassociated S. chartreusis (ICBG377 and ICBG323) from our study and rooted with Nocardiopisis prasina (Figure 5). The phylogenetic tree revealed that $S$. chartreusis strains ICBG377 and ICBG323 are clustering close to the other five S. chartreusis strains (MH540322, HQ400614, NR114825, NR041216 and HQ398415), which were isolated from marine sediment, soil and marine sponge. Interestingly, compounds $\mathbf{1}, \mathbf{3}$ and $\mathbf{4}$ were produced by two geographically distant but phylogenetically close $S$. chartreusis strains, ICBG 377 isolated from ants in Brazil, and NA02069 isolated from marine sediment in China.

\section{Conclusions}

Streptomyces chartreusis ICBG377 produced streptazolin (1), its $E$-isomer (2), strepchazolin A (3), strepchazolin B (4) and cyclooctasulphur (5); while compound $\mathbf{5}$ was also produced by $S$. chartreusis ICBG323. The absolute configurations of $\mathbf{3}$ and $\mathbf{4}$ were unambiguously confirmed as $5 S, 6 S, 9 R$ and $5 S, 6 S, 9 S$, respectively, by means of VCD and DFT calculations, in agreement with recent data using X-ray crystallography and Mosher's analysis. In our study, the vibrational chiroptical spectroscopic analyses were carried out directly in solution and without the need of either single crystals or derivatizations, showing the advantage of VCD for the establishment of stereochemistry. The phylogenetic analysis corroborates that geographycally distant bacterial strains can encode the same biosynthetic gene clusters for the production of natural products. The inorganic compound $\mathbf{5}$ was found to be the chemical defense

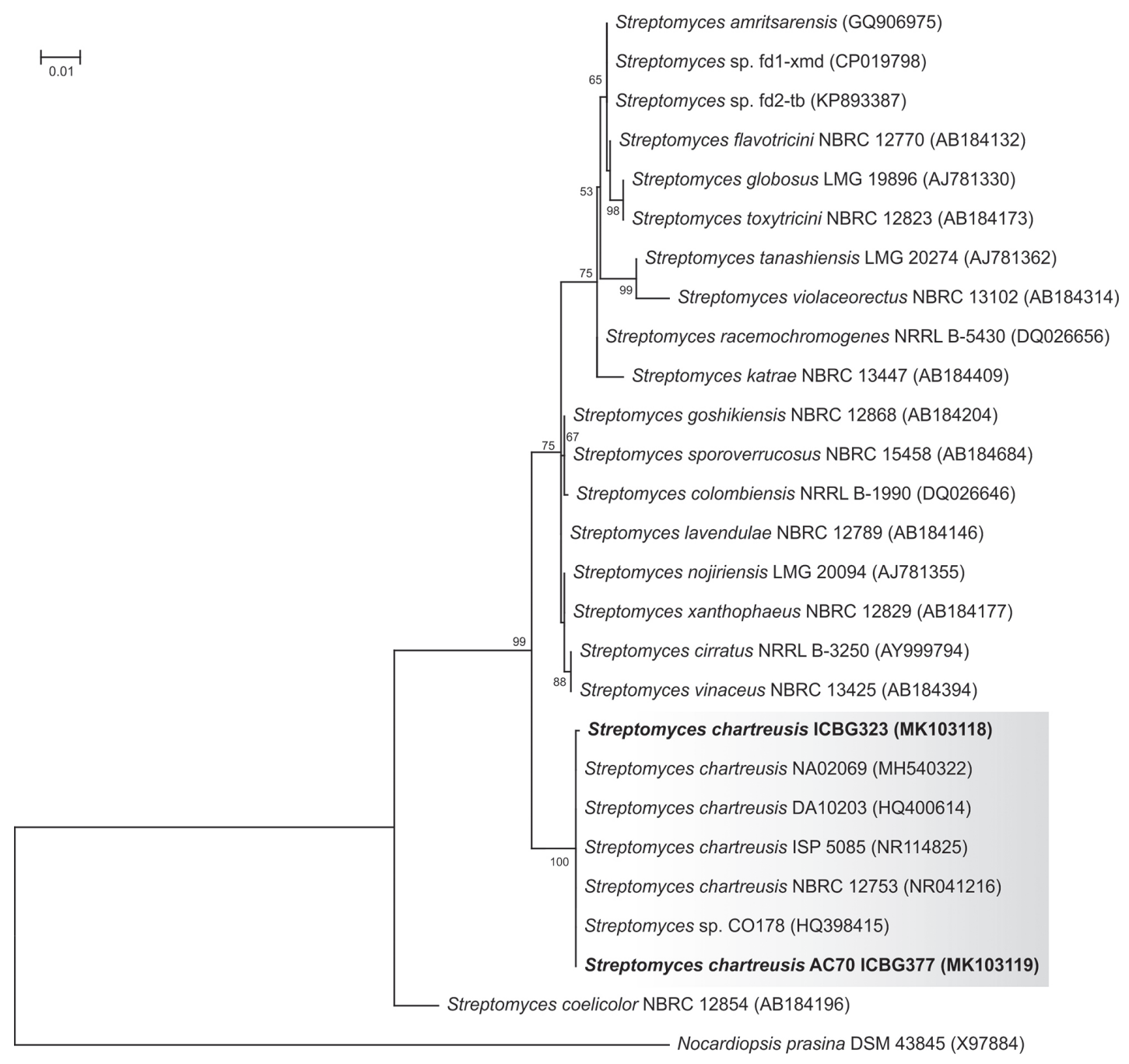

Figure 5. Phylogenetic tree including S. chartreusis strains (ICBG377 and ICBG323) based on $16 \mathrm{~S}$ rRNA sequence. Scale bar represents 0.01 substitutions per site. 
produced by both $S$. chartreusis strains to control the growth of the specialized pathogenic fungus Escovopsis sp. Compound $\mathbf{5}$ has been previously reported from a marine Streptomyces and is the most common allotrope of sulfur found in nature. The element sulfur has been demostrated as antimicrobial agent, therefore this corroborates the antifungal activity of $\mathbf{5}$ against Escovopsis.

\section{Experimental}

\section{General experimental procedures}

A HPLC system (Shimadzu, Kyoto, Japan) equipped with an LC-6AD solvent pump, an SCL 10AVB system controller, a CTO-10ASVP column oven, a Rheodyne model 7725 injector, an SPD-M10AVP diode array detector, a Class VP software for data acquisition, and an analytical column (Phenomenex, C6-Phenyl, $5 \mu \mathrm{m}, 250 \times 4.6 \mathrm{~mm}$ ). The HPLC purification were carried out at 3-6 $\mathrm{mL} \mathrm{min}^{-1}$ with a reversed-phase C6-phenyl semipreparative column (Phenomenex, C6-Phenyl, $5 \mu \mathrm{m}, 250 \times 10 \mathrm{~mm}$ ) using aqueous acetonitrile (ACN). Specific optical rotations were recorded in a P-2000 digital polarimeter (Jasco, Tokyo, Japan). The mass spectrometry data were acquired with a UPLC (Shimadzu) coupled to a micrOTOF II mass spectrometer (Bruker Daltonics). One- and two-dimensional NMR spectra were recorded with $500 \mathrm{MHz}$ (DRX-500) and $400 \mathrm{MHz}$ (DRX-400) spectrometers (Bruker UK, Coventry, UK) using deuterated chloroform, referenced to the internal solvent peak at $\delta_{\mathrm{H}} 7.26$ and $\delta_{\mathrm{C}} 77.16$. All solvents used in the study were of research grade quality or better. IR and VCD spectra of $\mathbf{3}$ and $\mathbf{4}$ were recorded with a Single-PEM Chiral IR-2X FT-VCD spectrometer (BioTools, Inc., Jupiter, USA) using a resolution of $4 \mathrm{~cm}^{-1}$ and a collection time of $8 \mathrm{~h}$. The optimum retardation of the $\mathrm{ZnSe}$ photoelastic modulator (PEM) was set at $1400 \mathrm{~cm}^{-1}$. Minor instrumental baseline offsets were eliminated from the final VCD spectrum by subtracting the VCD spectrum of each compound from that of the solvent obtained under identical conditions. The IR and VCD spectra were recorded in $\mathrm{abaF}_{2}$ cell with $100 \mu \mathrm{m}$ path length using methanol- $d_{4}$ as solvent. Samples were prepared using $5 \mathrm{mg}$ of each compound dissolved in $140 \mu \mathrm{L}$ of solvent. The gas chromatography spectrum of 5 was recorded in a gas chromatograph-mass spectrometer (Shimadzu, Kyoto, Japan).

Isolation and cultivation of bacteria

Collection of biological samples and research was authorized by Brazilian government (SISBIO authorization 46555-6, CNPq process 010936/2014-
9). Samples of the fungal garden of Acromyrmex subterraneus brunneus were collected in Ribeirão Preto, São Paulo state, Brazil (S 2110'13.0"; W 47050'49.4"; W-47.8470555556; S-21.1702777778), on August 2014; and winged males of Mycocepurus goeldii were collected in same region (S 21 ${ }^{\circ} 09^{\prime} 50.4^{\prime \prime}$; W 47 50'56.0'; W-47.848889; S-21.163889), on October 2015. The bacterial strain ICBG377 was isolated by vortexing small pieces of fungal garden of Acromyrmex subterraneus brunneus colony in $750 \mu \mathrm{L}$ of sterile deionized water, and subsequently spreading $100 \mu \mathrm{L}$ of this suspension onto chitin-agar plates containing antifungal $(0.05 \mathrm{~g}$ cycloheximide per liter of medium, and $0.04 \mathrm{~g}$ nystatin dissolved in dimethyl sulfoxide (DMSO)); while strain ICBG323 was isolated by vortexing winged males of Mycocepurus goeldii in $500 \mu \mathrm{L}$ sterile deionized water, and subsequently spreading $100 \mu \mathrm{L}$ of this suspension onto same chitin-agar plates. After 2-4 weeks of growth at $30^{\circ} \mathrm{C}$, bacterial colonies were sub-cultured onto ISP-2-agar plates, and serial culturing was done until pure cultures were obtained. ${ }^{24}$

\section{DNA extraction for bacterial identification}

Genomic DNA was extracted using a modified protocol. ${ }^{25}$ Actinobacteria were grown in $4 \mathrm{~mL}$ of liquid medium ISP-2 at $30{ }^{\circ} \mathrm{C}$ for $72 \mathrm{~h}$. After this period, the cultures were centrifuged at 5,000 g for $5 \mathrm{~min}$. The supernatant was discarded, and the culture pellet transferred to a $2.0 \mathrm{~mL}$ Eppendorf tube with $500 \mu \mathrm{L}$ of TE buffer 0.01X. It was added $3 \mu \mathrm{L}$ of RNase to digest the RNA and then added $400 \mu \mathrm{L}$ of solution I ( $1 \%$ Sarkosyl, $0.5 \mathrm{M} \mathrm{NaCl}, 1 \%$ sodium dodecyl sulfate (SDS)). The tubes were kept for $10 \mathrm{~min}$ at $37^{\circ} \mathrm{C}$ with continuous stirring. Then, $400 \mu \mathrm{L}$ of phenol:chloroform:isoamyl alcohol, 25:24:1 (PCI) were added and mixed by inversion and centrifuged at $10,000 \mathrm{~g}$ for $5 \mathrm{~min}$ at $37^{\circ} \mathrm{C}$, followed by carefully transferring the supernatant to a new $1.5 \mathrm{~mL}$ Eppendorf tube. Then, $10 \%$ of the total volume of sodium acetate (3 M, pH 5.2) and $60 \%$ isopropanol were added and gently mixed by inverting tube 5 to 10 times. Then the tubes were centrifuged for $5 \mathrm{~min}$ at $10,000 \mathrm{~g}$ at $37^{\circ} \mathrm{C}$. The DNA was precipitated in the pellet and the liquid removed. The pellet was washed with $1 \mathrm{~mL}$ of $70 \%$ ethanol and centrifuged at $10,000 \mathrm{~g}$ for $3 \mathrm{~min}$ at $37^{\circ} \mathrm{C}$. The supernatant was removed and the DNA after dried was resuspended in $20 \mu \mathrm{L}$ of TE $0.01 \mathrm{X}$.

Amplification - polymerase chain reaction (PCR)

The 16S rRNA gene was amplified from genomic DNA by polymerase chain reaction (PCR) using a pair of universal primers F27 (5'-AGAGTTTGATCATGGCTCAG-3') and 
R1492 (5'-TACGGTTACCTTGTTACGACTT-3'). ${ }^{26}$ The PCR reactions contained $2 \mu \mathrm{L}$ of DNA $\left(10 \mathrm{ng} \mu \mathrm{L}^{-1}\right)$, $2.0 \mu \mathrm{L}$ of each primer $(10 \mu \mathrm{M}), 2.5 \mu \mathrm{L}$ of $10 \mathrm{X}$ buffer, $2.0 \mu \mathrm{L}$ of $\mathrm{MgCl}_{2}(25 \mathrm{mM}), 4.0 \mu \mathrm{L}$ of dNTPs $(1.25 \mathrm{mM}$ each base), $0.2 \mu \mathrm{L}$ taq-polymerase $\left(5 \mathrm{U}^{-1} \mathrm{~L}^{-1}\right)$ and $10.3 \mu \mathrm{L}$ of sterile milli-Q water for a total volume of $25.0 \mu \mathrm{L}$. PCR was performed in a thermocycler (Applied Biosystems), in which amplification conditions were initiated by denaturation step with one cycle at $95{ }^{\circ} \mathrm{C}$ for $3 \mathrm{~min}$, followed by an annealing step and extension in 35 cycles at $95^{\circ} \mathrm{C}$ for $1 \mathrm{~min}, 60^{\circ} \mathrm{C}$ for $1 \mathrm{~min}$ and $72{ }^{\circ} \mathrm{C}$ for $2 \min$ and a final extension cycle at $72{ }^{\circ} \mathrm{C}$ for $15 \mathrm{~min}$, and maintained at $10{ }^{\circ} \mathrm{C}$. Amplification products were subjected to agarose gel electrophoresis $1 \%$ in $1 \mathrm{X}$ TBE buffer and stained with GelRed $^{\circledR}$ (Biotium, Fremont, USA). Purification was performed with ethylenediaminetetraacetic acid (EDTA)-ethanol.

\section{Amplification and purification of sequencing reaction}

The same primers $\mathrm{F} 27$ and R1492 and the inner primer U519F (5'-CAGCMGCCGCGGTAATWC-3') were used for the sequencing reaction of 16S rRNA gene. The reactions containing $2.0 \mu \mathrm{L} 5 \mathrm{X}$ buffer, $0.32 \mu \mathrm{L}$ of primer $(10 \mu \mathrm{M}), 0.3 \mu \mathrm{L}$ of BigDye ${ }^{\circledR} 3.1$ (Applied Biosystems, Waltham, USA), about $20 \mathrm{ng}$ of purified DNA and sterile Milli-Q water to complete a total volume of $10 \mu \mathrm{L}$. The thermocycler program consisted of 28 cycles at $95{ }^{\circ} \mathrm{C}$ for $15 \mathrm{~s}$, followed by $50{ }^{\circ} \mathrm{C}$ for $45 \mathrm{~s}$ and $60{ }^{\circ} \mathrm{C}$ for $4 \mathrm{~min}$, being completed and maintained at $10{ }^{\circ} \mathrm{C}$. The sequencing reaction was purified according to the instructions in the manual BigDye ${ }^{\circledR}$ (Applied Biosystems, Waltham, USA).

\section{Sequencing of the 16S rRNA gene and editing sequences}

The sequencing was performed in equipment ABI 3500 (Applied Biosystems, Waltham, USA). Sequences were edited and used to assemble the contigs in BioEdit 7.2.5. ${ }^{27}$ Contigs were used to search for homologous sequences in databases National Center for Biotechnology Information (NCBI) - GenBank ${ }^{28}$ and Eztaxon. ${ }^{29}$

\section{Phylogenetic analysis}

Phylogenetic and molecular evolutionary analyses were conducted in MEGA version $\mathrm{X},{ }^{30}$ using the maximum likelihood method based on the Tamura-Nei model and a discrete gamma distribution. The analysis involved 27 nucleotide sequences including $S$. chartreusis ICBG323 and ICBG377 and was rooted by Nocardiopsis prasina. All positions containing gaps and missing data were eliminated.
There were a total of 1342 positions in the final dataset. The DNA sequences were deposited in the NCBI-GenBank under accession numbers MK103118 (ICBG323) and MK103119 (ICBG377).

\section{Purification of compounds 1-5}

Strain ICBG377 was grown on solid ISP-2 medium (per liter: yeast extract, $4 \mathrm{~g}$; malt extract, $10 \mathrm{~g}$; glucose, $4 \mathrm{~g}$; agar, $20 \mathrm{~g})$ in 151 Petri plates $(140 \times 20 \mathrm{~mm}, 10.7 \mathrm{~L}$ total) for 10 days at $30{ }^{\circ} \mathrm{C}$. The solid agar was cut into small cubes and soaked three times in EtOAc overnight. The solvent was filtered and dried under vacuum to give the crude extract $(3.3 \mathrm{~g})$. The extract was dissolved in $90 \% \mathrm{MeOH}: \mathrm{H}_{2} \mathrm{O}(200 \mathrm{~mL})$, decanted and dried to give two fractions: A (soluble, $1.802 \mathrm{~g}$ ) and B (insoluble, $452.13 \mathrm{mg}$ ). Fraction A was purified by solid phase extraction (SPE)-C18 (55 $\mu \mathrm{m}, 10 \mathrm{~g} / 60 \mathrm{~mL}$, Phenomenex, Torrance, USA) using the following gradient: $200 \mathrm{~mL}$ (10\% $\left.\mathrm{MeOH}: \mathrm{H}_{2} \mathrm{O}, \mathrm{A} 1: 613.97 \mathrm{mg}\right) ; 200 \mathrm{~mL}\left(20 \% \mathrm{MeOH}: \mathrm{H}_{2} \mathrm{O}\right.$, A2: $97.68 \mathrm{mg}) ; 200 \mathrm{~mL}$ (40\% MeOH: $\mathrm{H}_{2} \mathrm{O}, \mathrm{A} 3: 43.93 \mathrm{mg}$ ); $200 \mathrm{~mL}\left(60 \% \mathrm{MeOH}: \mathrm{H}_{2} \mathrm{O}, \mathrm{A} 4: 82.61 \mathrm{mg}\right) ; 200 \mathrm{~mL}$ (80\% MeOH: $\left.\mathrm{H}_{2} \mathrm{O}, \mathrm{A} 5: 165.22 \mathrm{mg}\right) ; 200 \mathrm{~mL}(100 \%$ $\mathrm{MeOH}, \mathrm{A6}: 511.37 \mathrm{mg})$ and $200 \mathrm{~mL}(100 \%$ acetone, A7: $209.00 \mathrm{mg}$ ).

Fractions A1-A5 were combined and purified by semi-preparative HPLC using $\mathrm{C}_{6}$-Phenyl column $(5 \mu \mathrm{m}$, $250 \times 10 \mathrm{~mm}$ ) and the following gradient at $3 \mathrm{~mL} \mathrm{~min}^{-1}$ : 0-5 min, isocratic flow of $5 \% \mathrm{CH}_{3} \mathrm{CN}: \mathrm{H}_{2} \mathrm{O} ; 5-23 \mathrm{~min}$, linear gradient from $5 \% \mathrm{CH}_{3} \mathrm{CN}: \mathrm{H}_{2} \mathrm{O}$ to $50 \% \mathrm{CH}_{3} \mathrm{CN}: \mathrm{H}_{2} \mathrm{O}$; 23-24 min, linear gradient from $50 \% \mathrm{CH}_{3} \mathrm{CN}: \mathrm{H}_{2} \mathrm{O}$ to $100 \%$ $\mathrm{CH}_{3} \mathrm{CN}$; 24-25 min, isocratic flow of $100 \% \mathrm{CH}_{3} \mathrm{CN}$ and 25-26 min, from $100 \% \mathrm{CH}_{3} \mathrm{CN}$ to $5 \% \mathrm{CH}_{3} \mathrm{CN}: \mathrm{H}_{2} \mathrm{O}$ to give six fractions: C1 (9.4 mg), C2 (19.19 mg), C3 (25.66 mg), C4 (42.91 mg), C5 (7.29 mg), and C6 (58.74 mg).

Fraction C4 was purified by semi-preparative HPLC using $\mathrm{C}_{6}$-Phenyl column $(5 \mu \mathrm{m}, 250 \times 10 \mathrm{~mm})$ and an isocratic flow of $10 \% \mathrm{CH}_{3} \mathrm{CN}$ at $6 \mathrm{~mL} \mathrm{~min}^{-1}$ to yield $\mathbf{1}$ $\left(1.77 \mathrm{mg}, \mathrm{t}_{\mathrm{R}}=22.6 \mathrm{~min}\right)$ and $\mathbf{2}\left(4.47 \mathrm{mg}, \mathrm{t}_{\mathrm{R}}=24.8 \mathrm{~min}\right)$.

Fraction $\mathrm{C} 2$ was further purified by semi-preparative HPLC using $\mathrm{C}_{6}$-Phenyl column $(5 \mu \mathrm{m}, 250 \times 10 \mathrm{~mm})$ and an isocratic flow of $10 \% \mathrm{CH}_{3} \mathrm{CN}$ at $6 \mathrm{~mL} \mathrm{~min}^{-1}$ to yield strepchazolin A (3) $\left(3.60 \mathrm{mg}, \mathrm{t}_{\mathrm{R}}=18.4 \mathrm{~min}\right)$ and strepchazolin B (4) (3.49 mg, $\left.\mathrm{t}_{\mathrm{R}}=16.7 \mathrm{~min}\right)$.

Fractions B, A6 and A7 showed activity against the Escovopsis sp. They were combined and purified by SPE-Si $(55 \mu \mathrm{m}, 10 \mathrm{~g} / 60 \mathrm{~mL}$, Phenomenex, Torrance, USA) using the following gradient: $100 \mathrm{~mL}$ (100\% hexane, B 1: $280.38 \mathrm{mg}) ; 100 \mathrm{~mL}$ (9:1 hexane:EtOAc, B2: $498.90 \mathrm{mg}) ; 100 \mathrm{~mL}(8: 2$ hexane:EtOAc, B3: $85.72 \mathrm{mg}) ; 100 \mathrm{~mL}(7: 3$ hexane:EtOAc, 
B 4: $22.14 \mathrm{mg}) ; 100 \mathrm{~mL}(6: 4$ hexane:EtOAc, B5: $55.07 \mathrm{mg}) ; 100 \mathrm{~mL}$ (1:1 hexane:EtOAc, B6: $7.33 \mathrm{mg})$; $100 \mathrm{~mL}$ (4:6 hexane:EtOAc, B7: $5.29 \mathrm{mg}$ ); $100 \mathrm{~mL}$ (2:8 hexane:EtOAc, B8: $5.62 \mathrm{mg}) ; 100 \mathrm{~mL}$ (100\% EtOAc, B9: $6.21 \mathrm{mg}$ ) and $100 \mathrm{~mL}$ (100\% MeOH, B10: $117.44 \mathrm{mg}$ ). The fraction B1 was purified by solubility: B1.1 (soluble in acetone, $268.03 \mathrm{mg}$ ) and B1.2 (insoluble in acetone, $12.35 \mathrm{mg}$ ). All fractions obtained were tested against the Escovopsis sp. The fraction B1.2 was active (see Figure S26, SI section). Gas chromatography mass spectrometry (GC-MS) analysis of the active fraction B1.2 was carried out revealing cyclooctasulfur (5) as major compound (Figure S24, SI section).

Strain ICBG323 was also grown on solid ISP-2 medium. A similar protocol was used for fractionation of crude extract and identification of the cyclooctasulfur (5) by GC-MS (Figure S25, SI section) from active fraction against Escovopsis.

\section{Computational methods}

All density functional theory (DFT) calculations were carried out at $298 \mathrm{~K}$ in methanol solution using the polarizable continuum model (PCM) in its integral equation formalism version (IEFPCM) incorporated in Gaussian 09 software. ${ }^{31}$ Calculations were performed for the arbitrarily chosen strepchazolin A (3) and strepchazolin B (4), as depicted in Figure 1. The conformational search was carried out at the molecular mechanics level of theory with the Monte Carlo algorithm employing the MM+ force field, incorporated in HyperChem 8.0.10 software. ${ }^{32}$ Initially, for strepchazolin A (3), nine conformers with a relative energy (rel E.) within $6 \mathrm{kcal} \mathrm{mol}^{-1}$ of the lowest-energy conformer were selected and geometry optimized at the B3LYP/PCM(MeOH)/6-31G(d) level. The conformers for strepchazolin B (4) were generated by inverting the configuration at C-9 for all conformers identified in the previous step for strepchazolin A (3). These conformers were then geometry optimized at the B3LYP/PCM(MeOH)/6-31G(d) level. Before IR and VCD calculations all conformers obtained for both diastereoisomers were further geometry optimized at the B3PW91/PCM(MeOH)/6-311G(d,p) level. The four conformers identified for each configuration with rel E. $<1.6 \mathrm{kcal} \mathrm{mol}^{-1}$, which corresponded to more than $97 \%$ of the total Boltzmann distributions, were considered for IR and VCD spectral calculations. In order to better reproduce experimental data recorded in methanol- $d_{4}$, the input structures were created with exchangeable hydrogens replaced with deuterium atoms. ${ }^{33}$ IR and VCD spectra were created using dipole and rotational strengths from Gaussian, which were calculated at the B3PW91/PCM(MeOH)/6-311G(d,p) level, and converted into molar absorptivities $\left(\mathrm{M}^{-1} \mathrm{~cm}^{-1}\right)$. The Boltzmann factor for each conformer was calculated based on Gibbs free energies. Each spectrum was plotted as a sum of Lorentzian bands with half-widths at half-maximum of $6 \mathrm{~cm}^{-1}$. The calculated wavenumbers were multiplied with a scaling factor of 0.98 and the final Boltzmannpopulation-weighted composite spectra were plotted using Origin 8 software. ${ }^{34}$

\section{Supplementary Information}

NMR and HRMS spectra of compounds 1-4 and GC-MS spectra of $\mathbf{5}$ is available free of charge via the internet at http://jbcs.sbq.org.br as a PDF file.

\section{Acknowledgments}

The authors acknowledge the financial support from São Paulo Research Foundation (FAPESP) grants No. 2013/50954-0, No. 2014/14095-6, No. 2015/07089-2, No. 2014/25222-9, No. 2015/01001-6, and No. 2017/05920-1; and Conselho Nacional de Desenvolvimento Científico e Tecnológico (CNPq grant No. 307147/2014-2). This study was financed in part by the Coordenação de Aperfeiçoamento de Pessoal de Nível Superior - Brasil (CAPES) - Finance Code 001. We thank Dr Sandra Verza (Centro de Estudos de Insetos Sociais UNESP-RC) for identification of the ants, Eduardo A. Silva Jr. and Lohan Valadares for helping fungal garden collection and Claudia C. de Macedo for technical assistance. This research was also supported by resources supplied by the Centre for Scientific Computing (NCC/GridUNESP) of the São Paulo State University (UNESP).

\section{References}

1. Schultz, T. R.; Brady, S. G.; Proc. Natl. Acad. Sci. 2008, 105, 5435.

2. Hölldobler, B.; Wilson, E. O.; The Ants, $1^{\text {st }}$ ed.; Harvard University Press: Cambridge, 1990.

3. Branstetter, M. G.; Ješovnik, A.; Sosa-Calvo, J.; Lloyd, M. W.; Faircloth, B. C.; Brady, S. G.; Schultz, T. R.; Proc. R. Soc. B 2017, 284, 1852.

4. Carr, G.; Derbyshire, E. R.; Caldera, E.; Currie, C. R.; Clardy, J.; J. Nat. Prod. 2012, 75, 1806.

5. Haeder, S.; Wirth, R.; Herz, H.; Spiteller, D.; Proc. Natl. Acad. Sci. 2009, 106, 4742.

6. Schoenian, I.; Spiteller, M.; Ghaste, M.; Wirth, R.; Herz, H.; Spiteller, D.; Proc. Natl. Acad. Sci. 2011, 108, 1955. 
7. Mendes, T. D.; Borges, W. S.; Rodrigues, A.; Solomon, S. E.; Vieira, P. C.; Duarte, M. C. T.; Pagnocca, F. C.; Biomed Res. Int. 2013, 2013.

8. Oh, D. C.; Poulsen, M.; Currie, C. R.; Clardy, J.; Nat. Chem. Biol. 2009, 5, 391.

9. Pupo, M. T.; Currie, C. R.; Clardy, J.; J. Braz. Chem. Soc. 2017, 28, 393.

10. N. L. Batista, A.; Santos, F. M.; Batista, J.; Cass, Q. B.; Molecules 2018, 23, 492.

11. Aoyama, Y.; Katayama, T.; Yamamoto, M.; Tanaka, H.; Kon, K.; J. Antibiot. 1992, 45, 875.

12. David, L.; Kergomard, A.; J. Antibiot. 1982, 35, 1409.

13. Uchida, H.; Nakakita, Y.; Enoki, N.; Abe, N.; Nakamura, T.; Munekata, M.; J. Antibiot. 1994, 47, 655.

14. Wu, Q.; Liang, J.; Lin, S.; Zhou, X.; Bai, L.; Deng, Z.; Wang, Z.; Antimicrob. Agents Chemother. 2011, 55, 974.

15. Drautz, H.; Zähner, H.; Kupfer, E.; Keller-Schierlein, W.; Helv. Chim. Acta 1981, 164, 1752.

16. Li, F.; Warshakoon, N. C.; Miller, M. J.; J. Org. Chem. 2004, 69, 8836.

17. Yamada, H.; Aoyagi, S.; Kibayashi, C.; J. Am. Chem. Soc. 1996, $118,1054$.

18. Grabley, S.; Kluge, H.; Hoppe, H. U.; Angew. Chem., Int. Ed. Engl. 1987, 26, 664.

19. Perry, J. A.; Koteva, K.; Verschoor, C. P.; Wang, W.; Bowdish, D. M.; Wright, G. D.; J. Antibiot. 2015, 68, 40.

20. Yang, C. L.; Wang, Y. S.; Liu, C. L.; Zeng, Y. J.; Cheng, P.; Jiao, R. H.; Bao, S. X.; Huang, H. Q.; Tan, R. X.; Ge, H. M.; Mar. Drugs 2017, 15, 244.

21. Batista, J. M.; Blanch, E. W.; Silva, V. B.; Nat. Prod. Rep. 2015, $32,1280$.

22. Dickschat, J. S.; Martens, T.; Brinkhoff, T.; Simon, M.; Schulz, S.; Chem. Biodivers. 2005, 2, 837.

23. Deshpande, A. S.; Khomane, R. B.; Vaidya, B. K.; Joshi, R. M.; Harle, A. S.; Kulkarni, B. D.; Nanoscale Res. Lett. 2008, 3, 221.
24. Poulsen, M.; Currie, C. R.; PLoS One 2010, 5, e8748.

25. Sharma, A. D.; Singh, J.; Anal. Biochem. 2005, 337, 354.

26. Ludwig, W.; Int. J. Food Microbiol. 2007, 120, 225.

27. Hall, T. A.; Nucleic Acids Symp. Ser. 1999, 41, 95.

28. https://blast.ncbi.nlm.nih.gov/Blast.cgi accessed on August 8, 2019.

29. https://www.ezbiocloud.net/taxonomy accessed on August 8, 2019.

30. Kumar, S.; Stecher, G.; Li, M.; Knyaz, C.; Tamura, K.; Mol. Biol. Evol. 2018, 35, 1547.

31. Frisch, M. J.; Trucks, G. W.; Schlegel, H. B.; Scuseria, G. E.; Robb, M. A.; Cheeseman, J. R.; Scalmani, G.; Barone, V.; Mennucci, B.; Petersson, G. A.; Nakatsuji, H.; Caricato, M.; Li, X.; Hratchian, H. P.; Izmaylov, A. F.; Bloino, J.; Zheng, G.; Sonnenberg, J. L.; Hada, M.; Ehara, M.; Toyota, K.; Fukuda, R.; Hasegawa, J.; Ishida, M.; Nakajima, T.; Honda, Y.; Kitao, O.; Nakai, H.; Vreven, T.; Montgomery Jr., J. A.; Peralta, J. E.; Ogliaro, F.; Bearpark, M.; Heyd, J. J.; Brothers, E.; Kudin, K. N.; Staroverov, V. N.; Kobayashi, R.; Normand, J.; Raghavachari, K.; Rendell, A.; Burant, J. C.; Iyengar, S. S.; Tomasi, J.; Cossi, M.; Rega, N.; Millam, J. M.; Klene, M.; Knox, J. E.; Cross, J. B.; Bakken, V.; Adamo, C.; Jaramillo, J.; Gomperts, R.; Stratmann, R. E.; Yazyev, O.; Austin, A. J.; Cammi, R.; Pomelli, C.; Ochterski, J. W.; Martin, R. L.; Morokuma, K.; Zakrzewski, V. G.; Voth, G. A.; Salvador, P.; Dannenberg, J. J.; Dapprich, S.; Daniels, A. D.; Farkas, Ö.; Foresman, J. B.; Ortiz, J. V.; Cioslowski, J.; Fox, D. J.; Gaussian 09, Revision A. 02; Gaussian, Inc., Wallingford, USA, 2009.

32. HyperChem 8.0.10; Hypercube, Inc., Gainesville, USA, 2011.

33. Sprenger, R. F.; Thomasi, S. S.; Ferreira, A. G.; Cass, Q. B.; Batista Jr., J. M.; Org. Biomol. Chem. 2016, 14, 3369.

34. Origin 8.0; OriginLab, Northampton, USA, 2007.

Submitted: March 6, 2019

Published online: August 15, 2019 